\title{
Activation of nuclear factor kappa B in peripheral blood mononuclear cells from malaria patients
}

\author{
Chuchard Punsawad ${ }^{1,6}$, Srivicha Krudsood ${ }^{2,6}$, Yaowapa Maneerat ${ }^{1,6}$, Urai Chaisri ${ }^{1}$, Noppadon Tangpukdee ${ }^{3,6}$, \\ Emsri Pongponratn ${ }^{1,6}$, Kwannan Nantavisai $^{4}$, Rachanee Udomsangpetch ${ }^{5,6}$ and Parnpen Viriyavejakul ${ }^{1,6^{*}}$
}

\begin{abstract}
Background: Malaria parasites and their products can activate a specific immune response by stimulating cytokine production in the host's immune cells. Transcription nuclear factor kappa B (NF-KB) is an important regulator for the control of many pro-inflammatory genes, such as interleukin-1 (IL-1) and tumor necrosis factor (TNF). The activation and expression of NF-KB p65 in peripheral blood mononuclear cells (PBMCs) of malaria patients were investigated and correlated with the levels of IL-10 and TNF to study the nature of NF-KB p65 and its linkage to inflammatory cytokines.
\end{abstract}

Methods: The sample group comprised 33 patients admitted with malaria caused by Plasmodium vivax $(n=11)$, uncomplicated Plasmodium falciparum $(n=11)$, and complicated Plasmodium falciparum $(n=11)$. Peripheral blood was collected at admission and on day 7 for PBMC isolation. Healthy subjects were used as a control group. The expressions of NF-KB p65 in the PBMCs from malaria patients and the plasma levels of IL-10 and TNF were measured by using enzyme-linked immunosorbent assay (ELISA). The immunofluorescence technique was used to determine NF-KB nuclear translocation.

Results: At admission, patients with $P$. vivax and uncomplicated $P$. falciparum had significantly elevated phosphoNF-kB p65 levels in the PBMCs compared with those of healthy controls. However, patients with complicated $P$. falciparum malaria had decreased levels of phospho-NF-KB p65. On day 7 post-treatment, significantly increased phospho-NF-KB p65 was found in the PBMCs of patients with complicated $P$. falciparum, compared with healthy controls. The plasma level of IL-10 was elevated in day 0 in patients with complicated $P$. falciparum malaria and was found to be negatively correlated with phospho-NF-KB p65 level $\left(r_{s}=-0.630, p=0.038\right)$. However, there was no correlation between phospho-NF-kB p65 expression and TNF level in patients with complicated $P$. falciparum malaria.

Conclusions: This is the first report demonstrating alterations in NF-KB p65 activity in the PBMCs of malaria patients. The altered lower features of NF-KB p65 in the PBMCs of patients with complicated $P$. falciparum at admission could be due to a suppressive effect of high IL-10 associated with complicated $P$. falciparum malaria.

Keywords: Malaria, Plasmodium falciparum, Plasmodium vivax, Nuclear factor kappa B, Peripheral blood mononuclear cells, Interleukin-10, Tumor necrosis factor

\footnotetext{
*Correspondence: parnpen.vir@mahidol.ac.th

'Department of Tropical Pathology, Faculty of Tropical Medicine, Mahidol

University, 420/6 Rajvithi Road, Bangkok 10400, Thailand

${ }^{6}$ Center for Emerging and Neglected Infectious Diseases, Mahidol University,

Bangkok 10400, Thailand

Full list of author information is available at the end of the article
}

\section{Biomed Central}

(c) 2012 Punsawad et al.; licensee BioMed Central Ltd. This is an Open Access article distributed under the terms of the Creative Commons Attribution License (http://creativecommons.org/licenses/by/2.0), which permits unrestricted use, distribution, and reproduction in any medium, provided the original work is properly cited. 


\section{Background}

Nuclear factor kappa B (NF- $k B$ ) plays a crucial role in immune and inflammatory responses, through the regulation of various genes involved in pro-inflammatory cytokines, adhesion molecules, chemokines, inducible enzymes, and apoptosis [1]. Mammals express five NF$\kappa B$ protein members: NF-kB-1 (p50), NF- $\mathrm{kB}-2$ (p52), Rel A (p65), Rel B, and c-Rel [2]. These proteins have a structurally conserved amino-terminal (300 amino-acid) region, containing dimerization, nuclear localization and DNA binding domains. In unstimulated cells, NF- $k B$ is bound to its inhibitor, the inhibitor kappa B (ІкB) protein, and it appears in the cytoplasm as an inactive form. Following stimulation, I $\mathrm{K} B$ is first phosphorylated by IкB kinase (IKK) and then rapidly degraded by the proteosome. Subsequently, activated NF- $\mathrm{KB}$ translocates into the nucleus, where it binds to the DNA regulatory site to regulate specific gene expressions $[2,3]$.

The process of malaria pathogenesis is very complex and still poorly understood. Several studies have indicated that the expression of adhesion molecules on vascular endothelial cells and the production of proinflammatory cytokines are closely linked to the activation of NF- $\kappa B$ protein transcription. It is already known that circulating mononuclear cells are involved in the immune responses and production of pro-inflammatory cytokines. Accumulated evidence has demonstrated that excessive production of pro-inflammatory mediators leads to systemic and organ-related pathological conditions. Previous studies have reported that levels of endogenous pyrogens such as interleukin-6 (IL-6), IL-1 $\beta$ and IL-8 were elevated in $P$. vivax and $P$. falciparum malaria infections [4-7]. The increasing serum TNF levels were reported to be associated with increased mortality in Malawian children with severe malaria [8]. Plasma TNF levels were also found to be higher in Gambian children [9]. A recent study of experimental $P$. falciparum infection in malaria-naïve individuals has shown a coordinated increase in the level of proinflammatory cytokines, including IFN- $\gamma$, IL-12 and IL-8 in the serum [10]. Previous in vitro studies have demonstrated that haemozoin (HZ) [11] and glycosylphosphatidylinositol (GPI) [12,13] can stimulate monocytes and macrophages to synthesize pro-inflammatory cytokines via NF- $\mathrm{B}$ p pathways [12], leading to rapid phosphorylation of IкB, with subsequent nuclear translocation of NF- $\kappa B$ [13]. Using a microarray methodology, it has been reported that the transcripts of Toll-like receptor signaling through NF- $\mathrm{kB}$ pathways was significantly upregulated in the peripheral blood mononuclear cells (PBMCs) of both experimentally and naturally acquired malaria infections [14]. Aside from the process of cytoadhesion and sequestration, the pathogenesis of malaria is associated with increased production of pro- inflammatory cytokines. Circulating mononuclear cells are known to be induced in the immune response, and are potent biological sensors of infection. No study has reported the expression of NF- $\mathrm{kB}$ in PBMCs from malaria patients and its association with circulating cytokines such as IL-10 and TNF. To elucidate this process, NF-kB p65 activity in the PBMCs of malaria patients was determined and correlated with the plasma levels of IL-10 and TNF as well as with pertinent clinical data.

\section{Methods}

\section{Malaria patients and healthy controls}

Thirty-three malaria patients admitted to the Hospital for Tropical Diseases, Faculty of Tropical Medicine, Mahidol University, Thailand, were included in this study. The patients were divided into three groups: (1) Plasmodium vivax malaria $(\mathrm{n}=11)$, classified based on a positive blood smear with $P$. vivax by microscopic examination, (2) uncomplicated Plasmodium falciparum malaria $(\mathrm{n}=11)$, classified based on a positive blood smear with $P$. falciparum, and no evidence of severe or complicated malaria, and (3) complicated Plasmodium falciparum malaria $(\mathrm{n}=11)$, defined by the WHO criteria [15]. Complicated malaria was defined as patients exhibiting one or more of the following manifestations: hyperparasitaemia ( $>250,000$ parasite $/ \mu \mathrm{l}$ ), hypoglycaemia (glucose $<22 \mathrm{nmol} / \mathrm{l}$ ), severe anaemia (haematocrit $<20 \%$ or haemoglobin $<7.0 \mathrm{~g} / \mathrm{dl}$ ), or increased serum level of creatinine of more than $3.0 \mathrm{mg} / \mathrm{dl}$. Cerebral malaria was defined as unrousable coma with positive asexual forms of $P$. falciparum in blood smears, with other causes of coma excluded. Eleven healthy volunteers living in Bangkok, a non-endemic malaria area, were recruited as the control group. This group had no history of malaria infection. Written informed consent was obtained from all patients or their legal representatives before enrollment in the study. The study protocol was approved by the Ethics Committee, Faculty of Tropical Medicine, Mahidol University (MUTM 2010-053-01).

\section{Blood collection}

Five milliliters $(\mathrm{ml})$ of peripheral blood was collected in heparinized tubes from the malaria patients on day 0 (pre-treatment) and day 7 (post-treatment) for PBMC isolation. In addition, $20 \mathrm{ml}$ of whole blood was obtained from the healthy controls for PBMC isolation, which were employed as unstimulated cells, to investigate the ability of malaria-patient sera to induce NF- $\mathrm{kB}$ activation. To prepare the sera from malaria patients, clotted blood was centrifuged at $1,700 \mathrm{~g}$ for $10 \mathrm{~min}$. The supernatant representing the serum was harvested and stored in an aliquoted state at $-80^{\circ} \mathrm{C}$. The serum was heatinactivated at $56^{\circ} \mathrm{C}$ for $30 \mathrm{~min}$ before use. 


\section{Preparation of PBMCs}

PBMCs were isolated from freshly heparinized blood by gradient centrifugation, using Isoprep $^{\circledR}$ separation medium (Robbins Scientific, CA, USA), according to the manufacturer's instructions. The heparinized blood samples were centrifuged at $1,700 \mathrm{~g}$ for $5 \mathrm{~min}$ and plasma was removed and stored at $-80^{\circ} \mathrm{C}$ until use for cytokine measurements. The remaining blood samples were diluted with an equal volume of phosphate-buffered saline (PBS) $(\mathrm{pH} 7.4)$, layered carefully into a conical tube containing Isoprep ${ }^{\circledR}$ solution, then centrifuged at $1,200 \mathrm{~g}$ for $25 \mathrm{~min}$. After centrifugation, the PBMCs were removed and washed three times with PBS. The cells were stained with trypan blue and counted with a haemocytometer to determine the number of viable PBMCs.

\section{Total protein extraction}

PBMCs were suspended in ice-cold lysis buffer (Cell Signaling, MA, USA) (20 mM Tris- $\mathrm{HCl}, 150 \mathrm{mM} \mathrm{NaCl}$, $1 \mathrm{mM} \mathrm{Na}{ }_{2}$ EDTA, $1 \mathrm{mM}$ EGTA, 1\% Triton, $2.5 \mathrm{mM}$ sodium pyrophosphate, $1 \mathrm{mM} \beta$-glycerophosphate, $1 \mathrm{mM}$ $\mathrm{Na}_{3} \mathrm{VO}_{4}, 1 \mu \mathrm{g} / \mathrm{ml}$ leupeptin) and a protease inhibitor cocktail (Sigma-Aldrich, MO, USA) for $5 \mathrm{~min}$. The lysates were briefly sonicated on ice, centrifuged at $14,000 \mathrm{~g}$ for $10 \mathrm{~min}$ at $4^{\circ} \mathrm{C}$, and the supernatants were harvested. Protein concentrations in each sample were determined by Bradford assay (Pierce Biotechnology, IL, USA), using bovine serum albumin (BSA) as the standard.

\section{Measurement of total- and phospho-NF-KB p65}

The expression of NF-kB p65 in the PBMCs was assessed by sandwich ELISA kit (Cell Signaling, MA, USA) according to the manufacturer's protocol. Total cell proteins $(10 \mu \mathrm{g} /$ well $)$ were added into a 96-well microplate coated with total-/phospho-NF-кB p65 mouse monoclonal antibody and incubated for $2 \mathrm{~h}$ at $37^{\circ} \mathrm{C}$. The plate was then washed with PBS containing $0.05 \%(\mathrm{w} / \mathrm{v})$ Tween-20 (PBS-T) and $100 \mu \mathrm{l}$ of total/phospho-NF-kB p65 rabbit monoclonal antibody was added to the wells and incubated for $1 \mathrm{~h}$ at $37^{\circ} \mathrm{C}$ to detect the captured total-/phospho-NF- $\mathrm{B}$ p 65 protein. After washing with PBS-T, $100 \mu$ lof anti-rabbit IgG secondary antibody conjugated with horseradish peroxidase (HRP) was added and incubated for $30 \mathrm{~min}$ at $37^{\circ} \mathrm{C}$. To develop the reaction, $100 \mu \mathrm{l}$ of 3,3,5,5'-tetramethylbenzidine (TMB) substrate (Cell Signaling, MA, USA) was added and incubated for $10 \mathrm{~min}$ at $37^{\circ} \mathrm{C}$. Finally, $100 \mu \mathrm{l}$ of $0.18 \mathrm{M}$ sulfuric acid was added to stop the reaction. The optical density (OD) of the yellow-colored product was determined with a microplate reader at $450 \mathrm{~nm}$. All assays were carried out in duplicate.

\section{Determination of NF-KB p65 nuclear translocation}

The translocation of NF- $\mathrm{kB}$ p 65 from the cytoplasm to the nucleus was examined by immunofluorescence. PBMCs were smeared on adhesive slides coated with 3aminopropyltriethoxysilane (Sigma-Aldrich, MO, USA) and fixed with $3.7 \%$ formaldehyde in PBS ( $\mathrm{pH} 7.4)$ for $20 \mathrm{~min}$ at room temperature. After fixation, the cells were permeabilized with $0.5 \%$ Triton X-100 for $10 \mathrm{~min}$. After washing with PBS, the slides were blocked with 5\% BSA for $30 \mathrm{~min}$ at room temperature and incubated with mouse anti-human NF-KB p65 (F-6) monoclonal antibody (1:200) (Santa Cruz Biotechnology, Santa Cruz, $\mathrm{CA})$ for $1 \mathrm{~h}$ at $37{ }^{\circ} \mathrm{C}$. The slides were then incubated with goat anti-mouse antibodies conjugated with Alexa488 (1:1000) (Invitrogen, Carlsbad, CA) for $45 \mathrm{~min}$ at $37^{\circ} \mathrm{C}$. Finally, the slides were mounted with FluorSave ${ }^{\mathrm{TM}}$ reagent (Calbiochem, Nottingham, UK) and observed under a fluorescence microscope (Olympus BX 41, Tokyo, Japan) connected to a digital camera (Olympus DP 20, Tokyo Japan) and a standard UV filter set. Normal PBMCs stimulated with $50 \mathrm{ng} / \mathrm{ml}$ of TNF for 30 min were used as a positive control and the omission of primary antibody was used as a negative control. For quantitative analysis, PBMCs (approximately 200-300 cells) were randomly examined by fluorescence microscopy under high power $(\mathrm{x} 400)$ and cells stained positive for nuclear NF-kB p65 were counted. To calculate the percentage of cells with NF-kB nuclear translocation, the number of positive nuclear stained cells was divided by the total number of cell and the result was multiplied by 100.

\section{Measurement of IL-10 and TNF in plasma of malaria patients}

The levels of IL-10 and TNF in plasma was determined by the Human IL-10 and TNF ELISA Development Kit (Peprotech, NJ, USA), a quantitative sandwich enzyme immunoassay using a purified rabbit antibody against IL-10 or by TNF pre-coated onto an ELISA plate (Nunc Maxisorp F96, Roskilde, Denmark), and then incubated overnight at room temperature. Human recombinant IL10 and TNF protein at serial concentrations and 2-fold diluted plasma samples were incubated into the wells. Assay standards and samples were added to duplicate wells in the plate, which was incubated for $2 \mathrm{~h}$ at room temperature. After washing, either a biotinylated purified rabbit anti-human IL-10 or TNF antibody as the detection antibody was added to each well at a concentration of $50 \mathrm{ng} / \mathrm{ml}$ and incubated for $2 \mathrm{~h}$ at room temperature. Then, an avidin-horseradish peroxidase (HRP) conjugate was added to the wells and incubated for $30 \mathrm{~min}$ at room temperature. For color development, 2,2'-azino-bis (3-ethylbenzothiazoline-6-sulfonic acid), or ABTS liquid substrate (Sigma-Aldrich, MO, USA), was added and 
incubated at room temperature. Absorbance was read at $405 \mathrm{~nm}$ with wavelength correction set at $650 \mathrm{~nm}$. The sensitivity of the kit was within the range of 32$2000 \mathrm{pg} / \mathrm{ml}$ for IL-10 and 16-2000 pg/ml for TNF.

\section{Induction of NF-KB activation in healthy volunteer PBMCs} by malaria patient sera

To investigate whether the sera from malaria patients could induce the expression of NF-kB p65 in PBMCs of healthy volunteers, PBMCs $\left(2 \times 10^{6}\right.$ cells $)$ were separately stimulated by $10 \%$ sera from healthy controls and patients with $P$. vivax, uncomplicated $P$. falciparum, and complicated $P$. falciparum malaria for 0,30 , and $60 \mathrm{~min}$, at $37^{\circ} \mathrm{C}, 5 \% \mathrm{CO}_{2}$. TNF $(50 \mathrm{ng} / \mathrm{ml})$ was used as positive control. After incubation, PBMCs were washed with PBS and total proteins were isolated to detect the phosphoNF-кB p65 using sandwich ELISA.

\section{Statistical analysis}

Data were expressed as mean \pm standard error of the mean (SEM). The normality of distribution was determined by the Kolmogorov-Smirnov test. Differences in NF- $\mathrm{kB}$ p65 levels between groups were compared by unpaired Student's $t$-test. Student's paired $t$-test was used to assess differences in NF-kB p65 within groups. Differences in IL-10 and TNF cytokine levels between groups were analysed by the Mann-Whitney test and the Wilcoxon signed-rank test was used to compare the difference in cytokine levels within groups between day 0 and day 7 . In addition, the correlations within groups between levels of NF- $\mathrm{KB}$ p65 and pertinent clinical data including age, days of fever, malaria parasite density, RBC, WBC, haemoglobin, haematocrit, platelet, and cytokine levels were calculated using Spearman's rank correlation $\left(r_{s}\right)$. Data was analysed by statistical analysis performed using SPSS version 17.0 software (SPSS, IL, USA). The $p$ value $<0.05$ was considered significantly different.

\section{Results}

\section{Study subjects}

The clinical and laboratory parameters of malaria patients and healthy controls are shown in Table 1. On admission, the mean parasite density was significantly higher in patients with complicated P. falciparum malaria compared to those with uncomplicated $P$. falciparum infection $(p=0.001)$. Patients diagnosed with $P$. vivax malaria were administered chloroquine and primaquine, whereas patients with $P$. falciparum malaria were treated with artesunate and mefloquine. On day 7 post-treatment, no asexual forms of malaria parasites were found in the peripheral blood of all malaria patient groups. Complications in patients with complicated P. falciparum malaria included pulmonary oedema (four of 11, 36.4\%), cerebral malaria (six of 11,54.5\%), acute renal failure (six of 11 ,
$54.5 \%$ ), shock (three of $11,27.3 \%$ ), anaemia (six of 11 , $54.5 \%$ ), and acidosis (one of $11,9.1 \%$ ).

\section{Activation of NF-кB p65 in the PBMCs of malaria patients} The total-NF- $\kappa B$ p65 levels detected in the PBMCs was similar in all experimental groups $(p>0.05)$ on both day 0 and day 7 (Figure 1A). At admission, phospho-NF- $\mathrm{B}$ p65 levels were significantly elevated in the PBMCs of patients with $P$. vivax $(0.182 \pm 0.04, p<0.001)$ and uncomplicated $P$. falciparum malaria $(0.250 \pm 0.10, p$ $<0.001)$, compared to the healthy controls $(0.104 \pm 0.04)$. However, the phospho-NF- $\mathrm{B}$ p 65 levels were significantly lower in the PBMCs of patients with complicated $P$. falciparum malaria on admission compared to day 7 post-treatment $(0.086 \pm 0.06, p=0.01)$. Among the patient groups, phospho-NF-kB p65 activity was significantly higher in the PBMCs of patients with uncomplicated $P$. falciparum malaria, compared to patients with $P$. vivax $(p=0.01)$ or complicated P. falciparum malaria $(p=0.001)$ (Figure $1 \mathrm{~B})$. On day 7 posttreatment, phospho-NF- $\mathrm{kB}$ p65 activity was significantly increased in the PBMCs of patients with complicated $P$. falciparum malaria, compared to the healthy controls $(0.197 \pm 0.03$ vs $0.103 \pm 0.01, p=0.002)$ (Figure 1B). Levels of phospho-NF-kB p65 remained significantly elevated in PBMCs of the patients with $P$. vivax $(0.151 \pm 0.01)$, whereas phospho-NF-kB p65 levels in PBMCs from patients with uncomplicated $P$. falciparum malaria showed an increasing trend, but this was not statistically significant $(p=0.210)$ when compared to healthy controls $(0.103 \pm 0.01)$. In addition, no difference in the level of phospho-NF-kB p65 was found between uncomplicated and complicated $P$. falciparum malaria on day $7(p>0.05)$. No correlation was observed in any group of patients between the level of phospho-NF- $\mathrm{kB}$ p65 and other clinical parameters such as age, days of fever, malaria parasite density, RBC, WBC, haemoglobin, haematocrit, and platelet levels.

\section{Nuclear translocation of NF-KB p65 in the PBMCs of malaria patients}

The work performed in the study demonstrated and confirmed nuclear translocation of NF- $\mathrm{kB}$ in the PBMCs from malaria patients by immunofluorescence assay (Figure 2A). The percentages of NF-kB p65 nuclear staining with immunofluorescence were consistent with the findings of phospho-NF-kB p65 determined by ELISA. At admission, the mean percentage of cells with NF-кB p65 nuclear translocation was significantly increased in patients with $P$. vivax and uncomplicated $P$. falciparum malaria, compared to healthy controls $(55.0 \pm 2.8 \%$ vs $44.8 \pm 5.4 \%$ vs $13.2 \pm 1.3 \%, p<0.001, p$ $<0.001$, respectively) (Figure $2 \mathrm{~B}$ ). However, on day 7 the mean percentage of cells with NF-kB p65 nuclear 
Table 1 Clinical and laboratory parameters of malaria patients and healthy controls

\begin{tabular}{|c|c|c|c|c|c|c|c|}
\hline & \multicolumn{2}{|c|}{ P. vivax } & \multicolumn{2}{|c|}{ Uncomplicated $P$. falciparum } & \multicolumn{2}{|c|}{ Complicated $P$ falciparum } & \multirow[t]{2}{*}{ Healthy controls } \\
\hline & Day 0 & Day 7 & Day 0 & Day 7 & Day 0 & Day 7 & \\
\hline Age (years) & \multicolumn{2}{|c|}{$25(18-36)$} & \multicolumn{2}{|c|}{$31(18-55)$} & \multicolumn{2}{|c|}{$35(18-57)$} & $26(21-33)$ \\
\hline Sex (Male/Female) & \multicolumn{2}{|c|}{$11 / 0$} & \multicolumn{2}{|c|}{$10 / 1$} & \multicolumn{2}{|c|}{$10 / 1$} & $7 / 4$ \\
\hline Duration of fever (days) & \multicolumn{2}{|c|}{$3(1-5)$} & \multicolumn{2}{|c|}{$5(2-9)$} & \multicolumn{2}{|c|}{$6(3-9)$} & None \\
\hline Parasitaemia $(/ \mu l)$ & 62,916 & 0 & 30,853 & 0 & $825,475^{\#}$ & 0 & None \\
\hline WBC $\left(10^{3} / \mu l\right)$ & 6.3 & 7.4 & 6.5 & 5.6 & $8.5^{*}$ & $8.5^{*}$ & 6.6 \\
\hline $\operatorname{RBC}\left(10^{6} / \mu \mathrm{l}\right)$ & 4.9 & 5.0 & $4.1^{*}$ & 4.1 & $4.2^{*}$ & $3.6^{*}$ & 5.1 \\
\hline Haematocrit (\%) & $39.2^{*}$ & $39.3^{*}$ & $32.2^{*}$ & 32.0 & $34.0^{*}$ & $28.2^{*}$ & 44.6 \\
\hline Haemoglobin (g/dl) & $13.2^{*}$ & 13.1 & $10.6^{*}$ & 10.4 & $11.6^{*}$ & $9.6^{*}$ & 14.3 \\
\hline Platelet $\left(10^{3} / \mu \mathrm{l}\right)$ & $97^{*}$ & 303 & $106^{*}$ & 353 & $36^{*}$ & $226^{*}$ & 245 \\
\hline
\end{tabular}

Data presented as mean. ( $n=11$ for each group).

"Significant difference $(p<0.05)$ vs uncomplicated $P$. falciparum malaria.

*Significant difference $(p<0.05)$ vs healthy controls.

A

Total-NF-кB p65

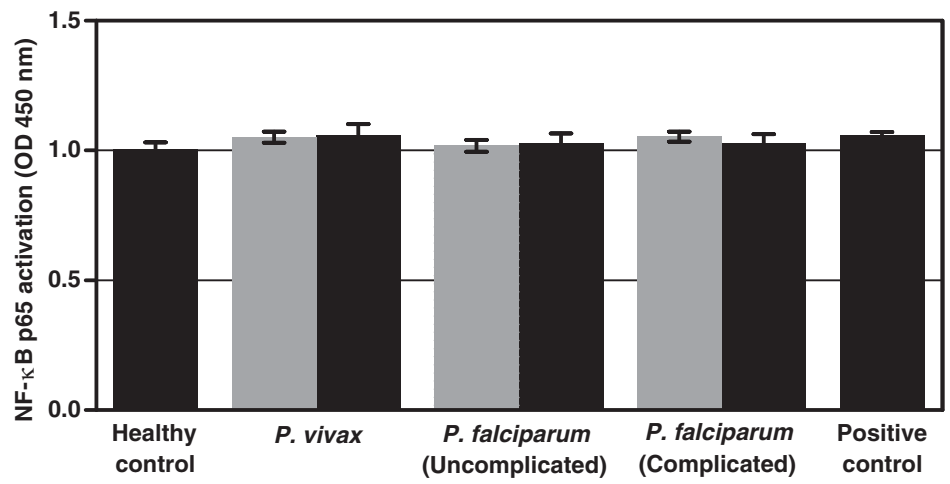

B

Phospho-NF-kB p65

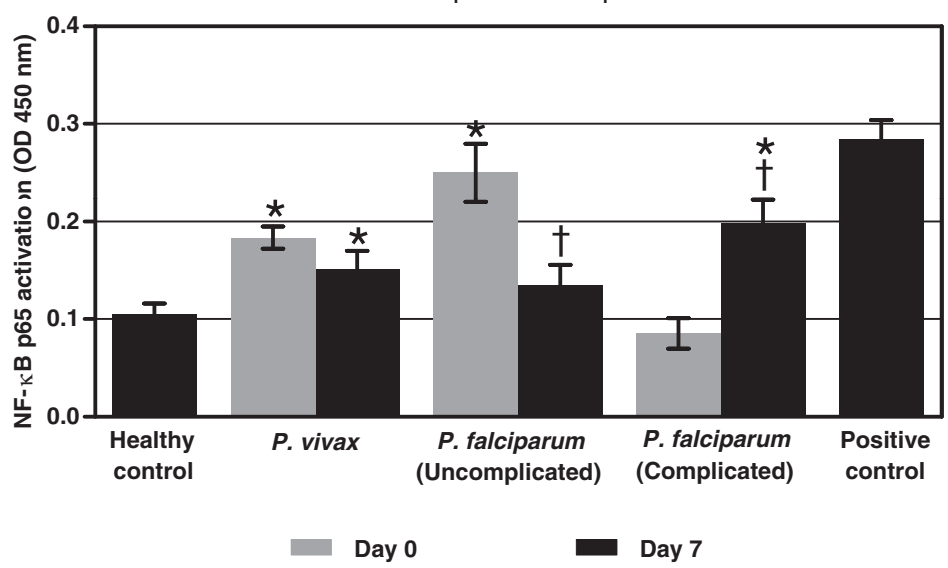

Figure 1 Activation of NF-KB p65 in the PBMCs of malaria patients determined by ELISA. (A) Total NF-kB level in the PBMCs of malaria patients ( $n=5$ for each group). No difference in total-NF-KB p65 level was observed in PBMCs of all malaria patient groups, $p>0.05$ compared with healthy controls (Student $t$-test). (B) Phospho-NF-kB p65 levels in the PBMCs of malaria patients on day 0 and day 7 ( $n=11$ for each group). Protein extract from PBMCs stimulated with $50 \mathrm{ng} / \mathrm{ml}$ of TNF for $30 \mathrm{~min}$ was used as a positive control. *Significance of $p<0.05$ compared with healthy controls (Student $t$-test), ${ }^{\dagger}$ Significance of $p<0.05$ compared with the day of admission (Student $t$-test). Data are presented as a mean \pm SEM. 


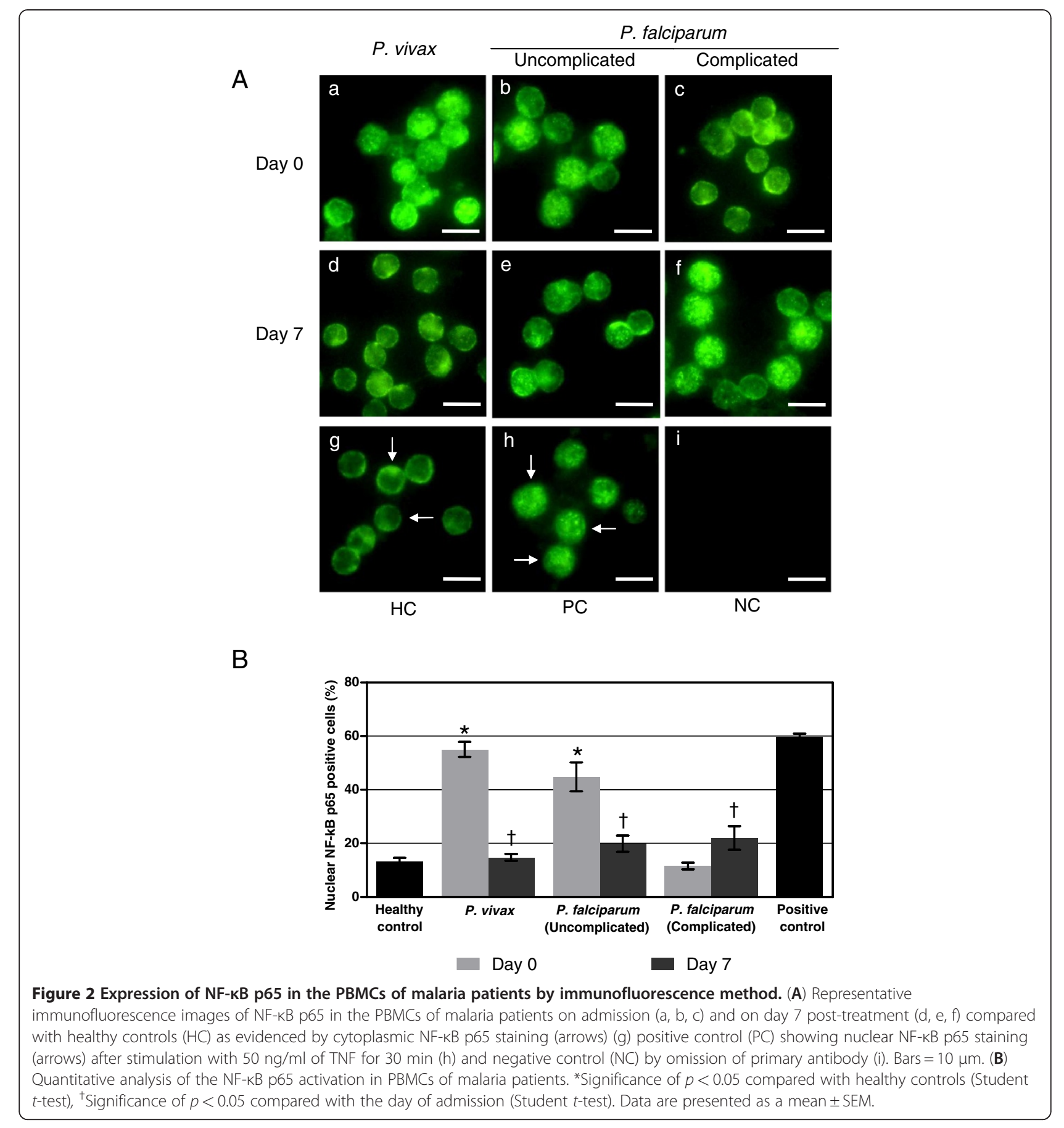

translocation in all patient groups was similar to healthy controls (Figure 2B).

\section{IL-10 and TNF levels in the plasma of malaria patients}

The expression levels of IL-10 and TNF in the plasma of malaria patients are presented in Figure 3. Complicated $P$. falciparum malaria had strikingly higher plasma IL-10 concentrations than $P$. vivax $(p<0.001)$ and uncomplicated P. falciparum $(p=0.002)$ patients during the acute illness (day 0). The mean plasma IL-10 on day 0 for $P$. vivax was $437.44 \pm 104.60 \mathrm{pg} / \mathrm{ml}$ as compared with uncomplicated P. falciparum $(630.13 \pm 183.78 \mathrm{pg} / \mathrm{ml})$ and complicated P. falciparum malaria patients $(1,898.80 \pm 666.50 \mathrm{pg} / \mathrm{ml})$ (Figure 3A). Nonetheless, levels of IL-10 in these malaria groups were significantly higher than those of the healthy controls $(8.20 \pm 5.96 \mathrm{pg} / \mathrm{ml}$, all $p<0.001)$. On day 7 , the mean plasma IL-10 in the three malaria groups declined significantly compared to their levels on day 0 


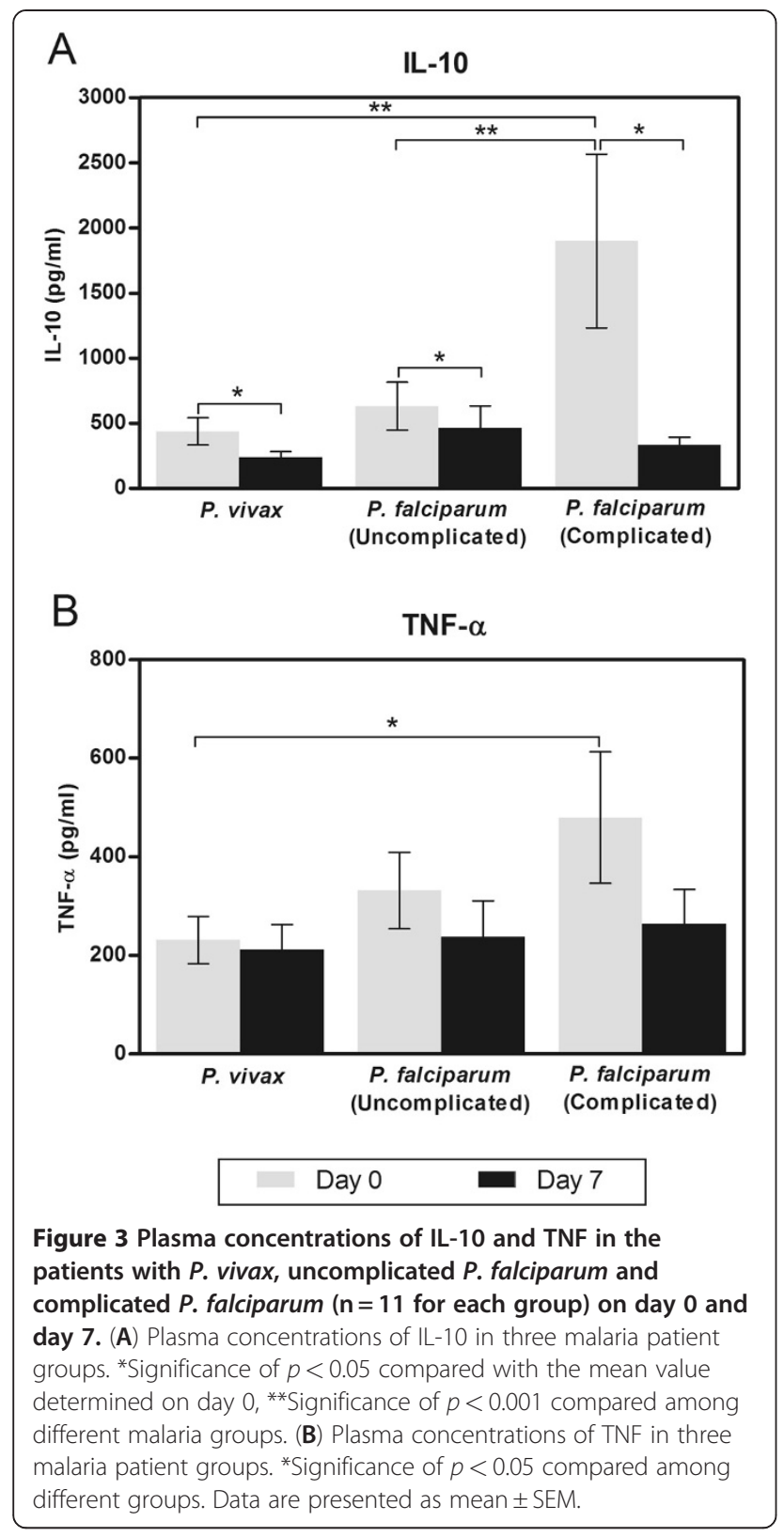

(day $7 ; 238.43 \pm 42.61 \mathrm{pg} / \mathrm{ml}$ for $P . \operatorname{vivax}(p=0.003)$, $464.30 \pm 169.00 \mathrm{pg} / \mathrm{ml}$ for uncomplicated $P$. falciparum $(p=0.041)$, and $331.26 \pm 61.41 \mathrm{pg} / \mathrm{ml}$ for complicated $P$. falciparum malaria patients $(p=0.010))$. The mean plasma levels of IL-10 in $P$. vivax patients were not significantly different from those observed in uncomplicated $P$. falciparum patients on both day $0(p>0.05)$ and day $7(p>0.05)$, and on day 7 of patients with complicated $P$. falciparum malaria $(p>0.05)$ (Figure 3A). Eventually, on day 7, circulating IL-10 levels were found to decline and returned to the same levels as for $P$. vivax and uncomplicated $P$. falciparum.
At admission, plasma TNF was markedly elevated in patients with $P$. vivax $(231.08 \pm 47.89 \mathrm{pg} / \mathrm{ml})$, uncomplicated $P$. falciparum $(331.70 \pm 77.55 \mathrm{pg} / \mathrm{ml})$, and complicated $P$. falciparum $(479.64 \pm 133.53 \mathrm{pg} / \mathrm{ml})$, compared with the healthy controls $(10.35 \pm 10.02 \mathrm{pg} / \mathrm{ml}$, all $p<0.001)$. The mean TNF concentration of patients with complicated P. falciparum was significantly higher than patients with $P$. vivax malaria $(p<0.05)$ (Figure $3 \mathrm{~B}$ ). TNF concentrations were monitored at day 7 and the levels were $211.19 \pm 51.73 \mathrm{pg} / \mathrm{ml}, 237.65 \pm 73.39 \mathrm{pg} / \mathrm{ml}$ and $263.95 \pm 70.25 \mathrm{pg} / \mathrm{ml}$ for $P$. vivax, uncomplicated $P$. falciparum and complicated $P$. falciparum malaria patients, respectively. TNF concentrations did not differ within each group of malaria patients at admission and day 7 post-treatment (all $p>0.05$ ) (Figure 3B). In addition, there was no correlation between the plasma levels of IL-10 and TNF in any malaria groups.

\section{Correlations between NF-KB p65 in PBMCs and plasma IL-10}

In complicated $P$. falciparum malaria, a significant negative correlation between phospho-NF- $\mathrm{kB}$ p65 in PBMCs and plasma level of IL-10 $\left(r_{s}=-0.630, p=0.038\right)$ was established during acute illness. No correlation was observed between phospho-NF-kB p65 in PBMCs and plasma TNF in any of the malaria groups.

\section{Effect of malaria serum on NF-KB p65 in the PBMCs of healthy controls}

The level of phospho-NF-kB p65 in the PBMCs increased significantly in response to sera from all malaria patient groups ( $P$. vivax, uncomplicated $P$. falciparum, and complicated $P$. falciparum malaria) at $30 \mathrm{~min}$ after stimulation (Figure 4) with the highest stimulation by sera from uncomplicated $P$. falciparum malaria. In addition, the levels of phospho-NF-kB p65 activation induced by sera from patients with uncomplicated $P$. falciparum malaria were significantly higher than those induced by sera from patients with complicated $P$. falciparum malaria $(p=0.044)$. However, this effect seems to be transient. In the present study, the level of phospho-NF-kB p65 induced by sera from patients showed a tendency to return to the pre-stimulation state after $60 \mathrm{~min}$ (Figure 4).

\section{Discussion}

This is the first report showing NF- $\mathrm{kB}$ expression in the PBMCs of malaria patients and its correlation with IL-10 and TNF by using sandwich ELISA. The use of ELISA has become a powerful method for measuring protein phosphorylation. ELISA is more quantitative than Western blotting and possesses high specificity and sensitivity due to the use of two antibodies specific for the target protein employed together in the sandwich. NF-kB p65 activation 


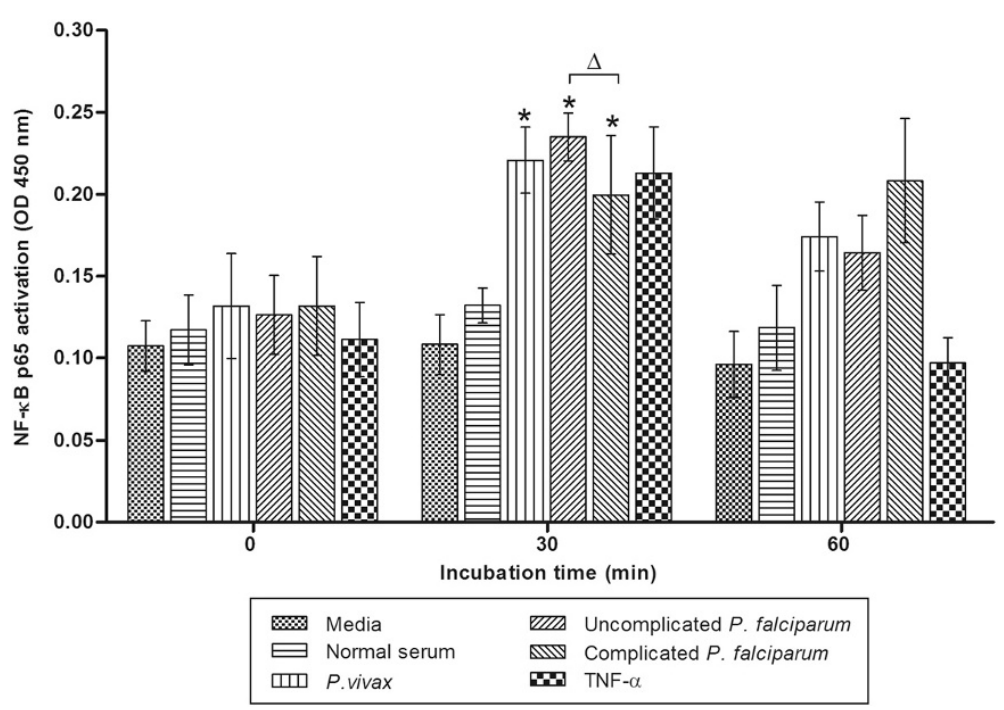

Figure 4 Malaria sera-induced NF-KB p65 activation in the PBMCs of healthy controls $(\mathbf{n}=\mathbf{5})$. The protein extracts $(10 \mu \mathrm{g} / \mathrm{well})$ of the PBMCs from healthy controls after stimulation with serum from malaria patients were analysed for phospho-NF-KB level using ELISA. The results demonstrated significantly increased levels of phospho-NF-KB p65 in the PBMCs in response to malaria-patient sera after 30 min of stimulation with $10 \%$ serum from malaria patients with $P$. vivax, uncomplicated $P$. falciparum, and complicated $P$. falciparum malaria. TNF treatment was used as positive control and PBMCs treated with media was used as untreated or negative control. * Significance of $p<0.05$ compared to normal serum treatments (Student $t$-test). ${ }^{\Delta}$ Significance of $p<0.05$ compared between groups. Data are presented as mean \pm SEM.

was increased in the PBMCs of $P$. vivax and uncomplicated $P$. falciparum patients, on both day 0 and day 7 , whereas in complicated $P$. falciparum patients, elevated NF-kB p65 activity was observed only on day 7 post-treatment. NF-kB activation may be triggered by various ligands or proteins of malaria parasites that induce up-regulation of the NF- $\mathrm{KB}$ signaling pathway, leading to nuclear translocation of NF$\mathrm{KB}$ and regulation of gene expression. It is possible that the increased NF- $\kappa B$ p65 levels in the PBMCs with malaria infection are involved in the enhancement of inflammatory cytokines. Consistent with the increased level of phosphoNF- $\mathrm{kB}$ p65 in the PBMCs, the immunofluorescence assay confirmed NF- $\mathrm{kB}$ p65 immunostaining in PBMC nuclei, indicating the active NF- $\mathrm{kB}$ protein state in malaria infection. Data from the literature of experimental in vitro malaria studies show that the mechanisms induced or involved in the activation of NF-kB p65 include haemozoin (HZ)induced enhancement of inflammatory cytokines [11,1618], activation of matrix metalloproteinase-9 (MMP-9) in human monocytes fed with trophozoites and HZ [19], and P. falciparum glycosylphosphatidylinositol (GPI) stimulating monocytes and macrophages, leading to the activation of NF- $\mathrm{kB}$ downstream signaling pathways induced expression of pro-inflammatory mediators, such as TNF, IL-6, IL12 , and nitric oxide (NO) $[12,13]$. Recent investigations studied the innate immune response in malaria infection, showing that Toll-like receptor 1 (TLR1), TLR2, and TLR4 were induced in PBMCs from both experimentally $[14,20]$ and naturally acquired malaria infections [14]. These findings suggest that the activation of TLRs by GPI [21] and
HZ [22] transmit signals in an intracellular pathway leads to the activation of transcription factor NF- $\mathrm{kB}$, which in turn propagates a signal to the nucleus to regulate the expression of pro-inflammatory cytokines. Consequently, these actions could cause increased levels of phospho-NF$\kappa B$ p65 and nuclear translocation of NF- $\mathrm{kB}$ p65 in the PBMCs of malaria patients.

NF-kB p65 activity was decreased in PBMCs from patients with complicated $P$. falciparum at admission, consistent with the reduced mean percentage of NF- $\mathrm{kB}$ p65 nuclear translocation evidenced by the immunofluorescence study. These findings agree with previous reports which demonstrated that PBMCs from patients with sepsis and major trauma reduced the active form of NF- $k B$ p 65 on the day of admission $[23,24]$. The silencing of NF- $\mathrm{kB}$ p65 gene expression reported in severe systemic inflammation may also explain the important signaling event in complicated P. falciparum wherein NF-kB p65 could be repressed by cytokines [25]. Studies have shown that immunosuppressives such as TGF- $\beta$ $[26,27]$ and IL-10 (also known as anti-inflammatory cytokine) [28] reportedly alter NF- $\mathrm{BB}$ expression and translocation, and contribute to cell desensitization [2628]. Normally, IL-10 is produced by macrophages as well as $\mathrm{T}$ and $\mathrm{B}$ lymphocytes, and has been shown to play a significant role in immunoregulation, involving negative feedback on the production of pro-inflammatory cytokine [29]. It has been reported that increasing plasma IL-10 was detected in cerebral and severe malaria patients at admission, in contrast to the patients with 
uncomplicated $P$. falciparum malaria [30]. Elevated IL10 levels have been detected in serum of Thai patients with acute $P$. falciparum malaria prior to treatment and the levels were found to return to normal after malaria treatment [31]. To investigate whether the decrease in nuclear translocation of NF-kB found in complicated $P$. falciparum malaria patients is linked to plasma IL-10 levels, IL-10 levels were determined in the malaria groups. In this study, the plasma level of IL-10 was significantly elevated in complicated $P$. falciparum malaria infection and had a negative correlation with phosphoNF- $k B$ p65 expression at admission. When the IL-10 levels were high, the phospho-NF-kB p65 levels were low. This correlation was not found in P. vivax or uncomplicated $P$. falciparum infections. At admission, the plasma levels of IL-10 in patients with complicated $P$. falciparum malaria were 4.3 times and 3 times higher than in patients with $P$. vivax and uncomplicated $P$. falciparum, respectively. This observation suggests that decreased levels of NF- $\mathrm{kB}$ p65 in the PBMCs of complicated $P$. falciparum patients during acute infection could be due to a negative feedback loop mechanism, or the consequence of high levels of IL-10, an important antiinflammatory cytokine associated with severe disease. It has been shown that IL-10 inhibits NF-kB activation rapidly and in a dose-dependent manner [28]. At day 7 post-treatment, the plasma levels of IL-10 in complicated P. falciparum malaria declined 5.7 times from the level on day 0 , to the same levels as the $P$. vivax and uncomplicated $P$. falciparum malaria groups. This trend is similar to results in a previous report [30]. The lower level of IL-10 could explain the elevated level of activated NF- $\mathrm{kB}$ in the PBMCs from complicated P. falciparum malaria at day 7 post-treatment.

Furthermore, the study investigated whether malaria patient serum could induce NF-kB p65 activation in unstimulated PBMCs. Significantly, transiently increased levels of phospho-NF- $\mathrm{kB}$ p 65 were found in the healthy PBMCs 30 min after stimulation with malaria serum, consistent with previous studies on endothelial cells [32], monocytes [33], and human cardiac myocytes [34]. However, the transient increased of phospho-NF-кB p65 in malaria sera-induced healthy PBMCS did not concur with the decline of NF-kB p65 at admission in complicated $P$. falciparum malaria. The PBMCs from healthy controls are naive and activation is short-lived. The effect might not be long enough to initiate a complex response to malaria serum. In contrary, the PBMCs collected from complicated $P$. falciparum malaria patients was sensitized by prolonged infection and response mechanisms induced by other cell signaling processes. The present study elucidates that sera from malaria patients can induce NF- $\mathrm{kB}$ p65 activation in naïve PBMCs. It would be helpful to further analyse the expression of NF- $\mathrm{kB}$ in PBMCs from malaria patients after stimulation with malaria sera to determine the event of "desensitization" in malaria. Further work to investigate whether pre-incubation of the malaria sera with an anti-IL-10 neutralizing monoclonal antibody would suppress NF- $\mathrm{kB}$ activation in PBMCs from complicated P. falciparum patients will be of interest.

\section{Competing interests}

The authors declare that they have no competing interests.

\section{Acknowledgements}

CP received a Research Assistantship (RA) scholarship from the Faculty of Graduate Studies, Mahidol University, Thailand. This study was funded by research grants from the Faculty of Tropical Medicine, year 2010, Mahidol University, Thailand, the Office of the Higher Education Commission, and Mahidol University under the National Research Universities Initiative, Thailand. We thank all of the staff at the Hospital for Tropical Diseases, Faculty of Tropical Medicine, Mahidol University, Thailand for their support throughout this study.

\section{Author details}

${ }^{1}$ Department of Tropical Pathology, Faculty of Tropical Medicine, Mahidol University, 420/6 Rajvithi Road, Bangkok 10400, Thailand. '2Department of Tropical Hygiene, Faculty of Tropical Medicine, Mahidol University, 420/6 Rajvithi Road, Bangkok 10400, Thailand. ${ }^{3}$ Department of Clinical Tropical Medicine, Faculty of Tropical Medicine, Mahidol University, 420/6 Rajvithi Road, Bangkok 10400, Thailand. ${ }^{4}$ Department of Microbiology, Faculty of Medicine, Srinakarinwiroj University, 114 Sukumvit 23, Bangkok 10110, Thailand. ${ }^{5}$ Department of Pathobiology, Faculty of Science, Mahidol University, 272 Rama VI Road, Ratchathewi, Bangkok 10400, Thailand. ${ }^{6}$ Center for Emerging and Neglected Infectious Diseases, Mahidol University, Bangkok 10400, Thailand

\section{Authors' contributions}

CP carried out the ELISA and immunofluorescence work, preliminary data analysis, and wrote the first draft of the manuscript. SK, NT and KN collected clinical data, supervised patient recruitment, critically analysed, and interpreted the data. YM, UC, EP and RU participated in the study design and manuscript preparation and revision. PV formulated the research idea, designed the experiments, gave laboratory and technical support, supervised, and revised the manuscript. All authors have approved the final version of the manuscript.

Received: 12 March 2012 Accepted: 10 June 2012

Published: 10 June 2012

\section{References}

1. Tripathi T, Aggarwal A: NF-kappa B transcription factor: a key player in the generation of immune response. Curr Sci India 2006, 90:519-531.

2. Baldwin AS: The NF-kappa B and I kappa B proteins: new discoveries and insights. Annu Rev Immunol 1996, 14:649-683.

3. Birbach A, Gold P, Binder BR, Hofer E, de Martin R, Schmid JA: Signaling molecules of the NF-kappa B pathway shuttle constitutively between cytoplasm and nucleus. J Biol Chem 2002, 277:10842-10851.

4. Friedland JS, Ho M, Remick DG, Bunnag D, White NJ, Griffin GE: Interleukin8 and Plasmodium falciparum malaria in Thailand. Trans $R$ Soc Trop Med Hyg 1993, 87:54-55.

5. Lyke KE, Burges R, Cissoko Y, Sangare L, Dao M, Diarra I, Kone A, Harley R, Plowe CV, Doumbo OK, Sztein MB: Serum levels of the proinflammatory cytokines interleukin-1 beta (IL-1beta), IL-6, IL-8, IL-10, tumor necrosis factor alpha, and IL-12(p70) in Malian children with severe Plasmodium falciparum malaria and matched uncomplicated malaria or healthy controls. Infect Immun 2004, 72:5630-5637.

6. Mshana RN, Boulandi J, Mshana NM, Mayombo J, Mendome G: Cytokines in the pathogenesis of malaria: levels of IL-I beta, IL-4, IL-6, TNF alpha and IFN-gamma in plasma of healthy individuals and malaria patients in a holoendemic area. J Clin Lab Immunol 1991, 34:131-139. 
7. Zeyrek FY, Kurcer MA, Zeyrek D, Simsek Z: Parasite density and serum cytokine levels in Plasmodium vivax malaria in Turkey. Parasite Immunol 2006, 28:201-207.

8. Grau GE, Taylor TE, Molyneux ME, Wirima JJ, Vassalli P, Hommel M, Lamber $\mathrm{PH}$ : Tumor necrosis factor and disease severity in children with falciparum malaria. N Engl J Med 1989, 320:1586-1591.

9. Kwiatkowski D, Hill AV, Sambou I, Twumasi P, Castracane J, Manogue KR, Cerami A, Brewster DR, Greenwood BM: TNF concentration in fatal cerebral, non-fatal cerebral, and uncomplicated Plasmodium falciparum malaria. Lancet 1990, 336:1201-1204.

10. Hermsen CC, Konijnenberg Y, Mulder L, Loe C, van Deuren M, van der Meer JW, van Mierlo GJ, Eling WM, Hack CE, Sauerwein RW: Circulating concentrations of soluble granzyme $A$ and $B$ increase during natural and experimental Plasmodium falciparum infections. Clin Exp Immunol 2003, 132:467-472.

11. Jaramillo M, Gowda DC, Radzioch D, Olivier M: Haemozoin increases IFNgamma-inducible macrophage nitric oxide generation through extracellular signal-regulated kinase- and NF-kappa B-dependent pathways. J Immunol 2003, 171:4243-4253.

12. Tachado SD, Gerold P, McConville MJ, Baldwin T, Quilici D, Schwarz RT, Schofield L: Glycosylphosphatidylinositol toxin of Plasmodium induces nitric oxide synthase expression in macrophages and vascular endothelial cells by a protein tyrosine kinase-dependent and protein kinase C-dependent signaling pathway. J Immunol 1996, 156:1897-1907.

13. Zhu J, Krishnegowda G, Gowda DC: Induction of proinflammatory responses in macrophages by the glycosylphosphatidylinositols of Plasmodium falciparum: the requirement of extracellular signal-regulated kinase, p38, c-Jun N-terminal kinase and NF-kappaB pathways for the expression of proinflammatory cytokines and nitric oxide. J Biol Chem 2005, 280:8617-8627.

14. Ockenhouse CF, Hu WC, Kester KE, Cummings JF, Stewart A, Heppner DG, Jedlicka AE, Scott AL, Wolfe ND, Vahey M, Burke DS: Common and divergent immune response signaling pathways discovered in peripheral blood mononuclear cell gene expression patterns in presymptomatic and clinically apparent malaria. Infect Immun 2006, 74:5561-5573.

15. WHO: Severe falciparum malaria. World Health Organization, Communicable Diseases Cluster. Trans R Soc Trop Med Hyg 2000, 94(Suppl 1):S1-90.

16. Pichyangkul S, Saengkrai P, Webster HK: Plasmodium falciparum pigment induces monocytes to release high levels of tumor necrosis factor-alpha and interleukin-1 beta. AmJTrop Med Hyg 1994, 51:430-435.

17. Prato M, Giribaldi G, Polimeni M, Gallo V, Arese P: Phagocytosis of haemozoin enhances matrix metalloproteinase- 9 activity and TNF alpha production in human monocytes: role of matrix metalloproteinases in the pathogenesis of falciparum malaria. J Immunol 2005, 175:6436-6442.

18. Deshpande P, Shastry P: Modulation of cytokine profiles by malaria pigmenthaemozoin: role of IL-10 in suppression of proliferative responses of mitogen stimulated human PBMC. Cytokine 2004, 28:205-213.

19. Prato M, Gallo V, Giribaldi G, Aldieri E, Arese P: Role of the NF-kappaB transcription pathway in the haemozoin- and 15-HETE-mediated activation of matrix metalloproteinase- 9 in human adherent monocytes. Cell Microbiol 2010, 12:1780-1791.

20. McCall MB, Netea MG, Hermsen CC, Jansen T, Jacobs L, Golenbock D, van der Ven AJ, Sauerwein RW: Plasmodium falciparum infection causes proinflammatory priming of human TLR responses. J Immunol 2007, 179:162-171.

21. Krishnegowda G, Hajjar AM, Zhu J, Douglass EJ, Uematsu S, Akira S, Woods AS, Gowda DC: Induction of proinflammatory responses in macrophages by the glycosylphosphatidylinositols of Plasmodium falciparum: cell signaling receptors, glycosylphosphatidylinositol (GPI) structural requirement, and regulation of GPI activity. J Biol Chem 2005, 280:8606-8616.

22. Coban C, Ishii KJ, Kawai T, Hemmi H, Sato S, Uematsu S, Yamamoto M, Takeuchi O, Itagaki S, Kumar N, Horii T, Akira S: Toll-like receptor 9 mediates innate immune activation by the malaria pigment haemozoin. J Exp Med 2005, 201:19-25.

23. Adib-Conquy M, Adrie C, Moine P, Asehnoune K, Fitting C, Pinsky MR, Dhainaut JF, Cavaillon JM: NF-kappaB expression in mononuclear cells of patients with sepsis resembles that observed in lipopolysaccharide tolerance. Am J Respir Crit Care Med 2000, 162:1877-1883.

24. Adib-Conquy M, Asehnoune K, Moine P, Cavaillon JM: Long-term-impaired expression of nuclear factor-kappa B and I kappa B alpha in peripheral blood mononuclear cells of trauma patients. J Leukoc Biol 2001, 70:30-38.
25. McCall CE, Yoza BK: Gene silencing in severe systemic inflammation. Am J Respir Crit Care Med 2007, 175:763-767.

26. Miller-Graziano CL, Szabo G, Griffey K, Mehta B, Kodys K, Catalano D: Role of elevated monocyte transforming growth factor beta (TGF beta) production in posttrauma immunosuppression. J Clin Immunol 1991 11:95-102.

27. Arsura M, Wu M, Sonenshein GE: TGF beta 1 inhibits NF-kappa B/Rel activity inducing apoptosis of $B$ cells: transcriptional activation of I kappa B alpha. Immunity 1996, 5:31-40.

28. Wang P, Wu P, Siegel MI, Egan RW, Billah MM: Interleukin (IL)-10 inhibits nuclear factor kappa B (NF kappa B) activation in human monocytes. IL-10 and IL-4 suppress cytokine synthesis by different mechanisms. J Biol Chem 1995, 270:9558-9563.

29. Ho M, Sexton MM, Tongtawe $P$, Looareesuwan $S$, Suntharasamai $P$, Webster HK: Interleukin-10 inhibits tumor necrosis factor production but not antigen-specific lymphoproliferation in acute Plasmodium falciparum malaria. J Infect Dis 1995, 172:838-844.

30. Peyron F, Burdin N, Ringwald P, Vuillez JP, Rousset F, Banchereau J: High levels of circulating IL-10 in human malaria. Clin Exp Immunol 1994, 95:300-303.

31. Wenisch C, Parschalk B, Narzt E, Looareesuwan S, Graninger W: Elevated serum levels of IL-10 and IFN-gamma in patients with acute Plasmodium falciparum malaria. Clin Immunol Immunopathol 1995, 74:115-117.

32. Bierhaus A, Hemmer CJ, Mackman N, Kutob R, Ziegler R, Dietrich M, Nawroth PP: Antiparasitic treatment of patients with $P$. falciparum malaria reduces the ability of patient serum to induce tissue factor by decreasing NF-kappa B activation. Thromb Haemost 1995, 73:39-48.

33. Li ZQ, Huang YS, Yang ZC, Wang JH: Effect of burn serum on the nuclear translocation of monocytic NF-kappaB p50/p65. Zhonghua Shao Shang Za Zhi 2004, 20:265-267.

34. Kumar A, Michael P, Brabant D, Parissenti AM, Ramana CV, Xu X, Parrillo JE: Human serum from patients with septic shock activates transcription factors STAT1, IRF1, and NF-kappaB and induces apoptosis in human cardiac myocytes. J Biol Chem 2005, 280:42619-42626.

doi:10.1186/1475-2875-11-191

Cite this article as: Punsawad et al:: Activation of nuclear factor kappa B in peripheral blood mononuclear cells from malaria patients. Malaria Journal 2012 11:191.

\section{Submit your next manuscript to BioMed Central and take full advantage of:}

- Convenient online submission

- Thorough peer review

- No space constraints or color figure charges

- Immediate publication on acceptance

- Inclusion in PubMed, CAS, Scopus and Google Scholar

- Research which is freely available for redistribution 